\title{
Evaluation of Optimal Wavelet De-noising Parameters to Predict Nutrient Content in Oil Palm Leaves using Spectroradiometer
}

\author{
Helena A. J. Jayaselan, Wan I. W. Ismail, Nazmi M. Nawi, and Abdul R. M. Shariff
}

\begin{abstract}
In order to reduce excessive fertiliser application, a non-destructive method of spectral data acquisition using spectroradiometer with wavelet analysis was explored to determine the level of nutrients in the oil palm leaves. In spectral data analysis, wavelet de-noising (WD) can be applied to remove background noises and other disturbances such as scattered light that may affect the results of data. Therefore, this study aims to determine and evaluate the best combination of parameters for $W D$, with respect to nutrients nitrogen $(N)$, phosphorus (P) and potassium (K). These nutrients were studied for three age groups of immature, mature, and old palms. The results were evaluated based on the highest value of coefficient of determination $\left(R^{2}\right)$ and lowest root mean square error (RMSE) of partial least square regression (PLSR) analysis. The prediction of nutrient content correlation was found to have tremendous improvement using the proposed technique when compared to the original spectra, with highest prediction $R^{2}$ value of 0.99 for $K$ of mature palms, 0.97 for $N$ of immature palms and 0.95 for $P$ of mature palms. The results of WD for nutrients prediction were found to be better than results from chemometric method of namely multiplicative scatter correction (MSC). It was observed that for each nutrient type and palm maturity level, there were different combination of parameters based on the highest $\mathbf{R}^{2}$ value that best suited them. Therefore, spectroradiometer assisted with optimal wavelet de-noising parameters gives excellent relationship between spectral data and nutrients $N, P$, and $K$.
\end{abstract}

Index Terms - De-noising Techniques, Oil Palm, Partial Least Square (PLS), Spectroradiometer, Wavelet Analysis.

\section{INTRODUCTION}

Oil palm is one of the most lucrative commercial crops planted widely in countries with good rainfall and sunshine throughout the year, such as Malaysia, Indonesia, and Africa [1]. The oil palm trees require sufficient amount of nutrients, especially nitrogen $(\mathrm{N})$ all year round, to be healthy and produce high yield [2]. Studies were conducted to research on the level of priority among $\mathrm{N}$, phosphorus (P), and potassium $(\mathrm{K})$ nutrients, which results in $\mathrm{K}$ being the highest, followed by $\mathrm{P}$ and then $\mathrm{N}$ for oil palm trees [3].

Nutrients N, P, and K were the three main macronutrients of interest that was highly focused in oil palm plantation. The

Submitted on March 30, 2021

Published on April 23, 2021.

Helena A. J. Jayaselan, Department of Biological \& Agricultural Engineering, Faculty of Engineering, Universiti Putra Malaysia, Malaysia.

(email: helena_anusia@yahoo.com)

Wan I. W. Ismail, Department of Biological \& Agricultural Engineering, Faculty of Engineering, Universiti Putra Malaysia, Malaysia.

(email: wiwi.ishak@gmail.com)

Abdul R. M. Shariff, Department of Biological \& Agricultural Engineering, Faculty of Engineering, Universiti Putra Malaysia, Malaysia.

(email: rashidsnml@gmail.com) deficiency of nutrients in oil palm trees can be affected by many factors including the type of soil, terrain, and climate [4], [5]. Nutrient deficiency in oil palm plantation negatively influences the yield of palm oil [6], [7]. Symptoms of $N$ deficiency includes leaves becoming small, pale green on the lower fronds, yellow ranchis and mid-ribs with narrow leaves that roll inwards with low frond count and lower yield. The $\mathrm{P}$ deficiency is clearly seen with short fronds and stunted growth and decreased trunk diameter with height. The $\mathrm{K}$ deficiency shows with orange spotting, mid-crown yellowing, or white stride while having a flat top, small frond size, and late crowning [8], [9].

Therefore, an optimum level of nutrient supply will not only produce a greater number of fresh fruit bunches (FFB) but also bigger and healthy ones [10, 11]. Tarmizi et al. [12] studied the effects of N, P, and K fertiliser application, on oil palm bunch components and found that, the lack of $\mathrm{N}$ adversely affects the number of bunches, bunch weight, and total oil per bunch. Hence, regular fertiliser application is important for best results in oil palm productivity and yield.

However, the conventional method of nutrient level determination using chemical analysis is destructive to the palm leaves and time consuming. For non-destructive researches, the spectroradiometer has been widely used as non-destructive sensor by various fields especially in agriculture for applications such as orange taste characterization [13], near infrared (NIR) to predict sugar content of sugarcane internodes [14], infrared (IR) for determination of virgin coconut oil from mixture of olive and palm oil [15], and determination of butylated hydroxytoluene in palm olein and palm oil [16]. Due to the high absorption by chlorophylls and carotenoids, the visible spectrum of around 400 to $700 \mathrm{~nm}$ had low leaf reflectance [17].

A significant relationship between macronutrients of $\mathrm{N}, \mathrm{P}$, $\mathrm{K}$, magnesium $(\mathrm{Mg})$, and calcium $(\mathrm{Ca})$ with reflectance is expected in green plants due to its influences in the process of photosynthesis [18], [19]. Four optical sensors were evaluated to estimate the nutrient contents in oil palm leaves which resulted in spectroradiometer being the better sensor when paired with partial least square regression (PLSR)

Nazmi M. Nawi, Institute of Plantation Studies, Universiti Putra Malaysia, Malaysia.

(email: nazmimat@upm.edu.my)

Funding: This work was supported by the Research University Grant Scheme (RUGS) [grant numbers 9387400] of Universiti Putra Malaysia; and United Plantations, Jenderata, Malaysia. 
analysis [20]. However, the results for PLSR were pretty low leaving room for improvements. Another study on oil palm leaf nutrients that used spectroradiometer and PLS with conventional statistical pre-processing techniques had better $\mathrm{R}^{2}$ and RMSE results with multiplicative scatter correction (MSC) for all nutrients in average [21]. Nevertheless, in the process of obtaining spectral data, the instrument and natural factors can impose abnormalities in the original spectra. This can result in inaccuracies when models go through the spectrum to predict the nutrient levels [22]. Therefore, noise removal is an important step before any interpretation or data analysis [23].

The wavelet transform (WT) is a dynamic tool of signal and image processing and is particularly suitable for the applications of non-stationary signals which may vary in time [24]. Wavelet de-noising (WD) method of fast wavelet transform was used in noise reduction of multichannel highresolution ECG signals in a study performed by Kania et al. [25]. The combination of Daubechies $(\mathrm{db})$ of order 1 with decomposition of levels of 1 to 4 and above as well as Symlet (sym) of order 3 and level 4 were among the best results. Another study by Aminghafari et al. [26] found that by combining db2 wavelets and level 6 with PCA when it was applied to multichannel neural recordings, the result exhibits promising behaviour on classical bench signals and seems to perform well.

The aim of noise removal is to reconstruct the original signal from a finite set of values (noisy signal) without assuming a particular structure for the signal [27]. Hence, this study focuses on the application of WD method on reflectance spectra of oil palm leaf for the detection of nutrients of different age groups of immature, mature, and old palms (5, 10 and 20 years old), using spectroradiometer sensor. A portable spectroradiometers has weaker signal and stronger noise compared to larger spectroscopes [28] Therefore, the objective of this study was 1 ) to determine the best combination of WD parameters for the spectral reflectance data of oil palm leaves that was obtained using portable spectroradiometer with respect to $\mathrm{N}, \mathrm{P}$, and $\mathrm{K}$; 2 ) to evaluate the WD results of partial least square regression (PLSR) analysis in terms of coefficient of determination $\left(\mathrm{R}^{2}\right)$ and root of mean square error (RMSE) with the raw spectral data and statistically (chemometrics) pre-processed spectral data with the proposed method of WD.

\section{A. Leaf Sampling}

\section{MATERIALS AND METHODS}

The materials for this study consist of three different age groups of 5, 10, and 20 years old (30 each group) of oil palms leaves, from frond number 17 (F17), representing a total of 90 samples. The sample size and sampling method was in accordance to leaf sampling unit (LSU) [29]. F17 was selected for nutrient assessment based on pioneer researches, as it gives good representation of an oil palm tree because it is the centre frond of the tree $[30,31]$. The study plot was on flat terrain of Banar Series soil, located the United Plantation (UP), Jenderata, Teluk Intan, Malaysia.

All the leaves that were collected were firstly subjected to a delicate cleansing action, to remove impurities that may be intact on the leaf cuticles, using a soft towel and distilled water. This action was taken to eliminate any partiality of the acquired data using spectroradiometer. 10 leaf samples, from both left and right side (5 leaves form each side) of the midsection of an oil palm frond were cut based on the conventional method for leaf sampling, as shown in Fig. 1. Then the leaves were carefully ice packed and sent to a laboratory for destructive method of nutrient content determination through conventional chemical analysis.

The laboratory at UP complies with the specified Malaysian standards (SIRIM, 1980) to determine the desired $\mathrm{N}, \mathrm{P}$ and $\mathrm{K}$ nutrient levels in leaves and soil. The flame photometric method was used for $\mathrm{K}$ and colorimetry for determination of $\mathrm{P}$, both using the atomic absorption spectrometer (AAS) (manufactured by Perkin Elmer at Waltham, Massachusetts, U.S) and the classic Kjeldahl method of digestion with the colorimetric determination for $\mathrm{N}$ was conducted using the titration method.

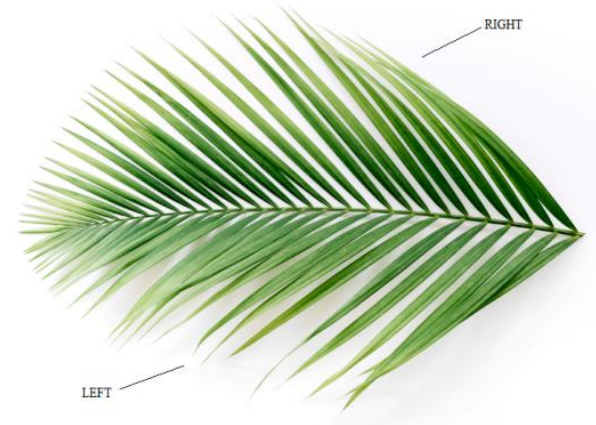

Fig. 1. Mid-section of an oil palm frond.

\section{B. Spectroradiometer Sensor}

Data acquisition was carried out using this sensor on a sunny day, from 8 am to $1 \mathrm{pm}$ in the month of March, just before the rainy season (March to September) in Peninsular Malaysia because palms were not in drought in this season. The sensor used for spectral data acquisition was a portable full range spectroradiometer (FRS) (Fieldspec 4) with wavelengths ranging from 350 to $2500 \mathrm{~nm}$. This device was adapted for the observation of nutrients $\mathrm{N}, \mathrm{P}$ and $\mathrm{K}$ since it was proven to be able to detect these nutrients with good correlation within these wavelengths by Pimstein et al. [32] and Bechlin et al., [33]. The spectroscopy sensor was manufactured by ASD, Boulder, Colorado, USA.

This portable FRS had the wavelength accuracy of $0.5 \mathrm{~nm}$ and wavelength reproducibility of $0.1 \mathrm{~nm}$. The contact probe had built-in halogen lamp and came with a clip-on feature for easy usage to obtain the raw spectral data with lesser external disturbance. An average of 10 spectral readings were taken every for each leaf to ensure data integrity of the outdoor field in unpredictable atmospheric conditions. The raw spectral data was then converted into percentage of reflectance using ViewSpec software.

\section{Wavelet De-noising}

Removal of noise while retaining the quality of processed signal or image is known as de-noising, whereas WD is a method of pre-processing of spectral data or signals using wavelet filters [27]. Different types and combination of 
parameters in WD were explored in search of the optimal pre-processing technique for oil palm leaf reflectance spectral with respect to N, P, and K nutrients. A total of 350 de-noising techniques with different combinations of parameters and wavelets were tested to find the best combination. The wavelets are functions that can scale and translate any signal into a WT that is considered as forms of time-frequency representation for continuous-time signals [34]. Because of the multi-resolution analysis and ability of denoting local characteristics of signal in both time domain and frequency domain of WT, it is called mathematical microscope for analysing signals [28].

The resulting WT is a representation of the signal at different scales that allows manipulation of features at different scales independently for suppressing or strengthening a particular feature. The de-noising technique using wavelets was found to have nearly optimal estimation of the noise-corrupted piecewise smooth signal [35]. The WD process involves three steps to transform the signal into wavelet domain through decomposition of the signal, thresholding of the wavelet coefficients and finally the inverse wavelet transform to reconstruct the signal [36]. WD is different from the traditional filtering approaches due the non-linear reflectance spectral [37]. De-noising technique using wavelets is quite different from the traditional filter approaches due to its non-linear thresholding step.

The method used here includes the combination of wavelet family, general thresholding, and specific thresholding algorithm, threshold rescaling as well as decomposition levels selections. Pre-processing of a signal using the denoising technique in wavelet analysis was based on the assumption that the amplitude rather than the location of the spectral is different from the noise [35]. In general, for an original spectral signal of $f(k)$ of length $\mathrm{L}$ that is corrupted with noise of $w(k)$ gives the noisy signal of $x(k)$ as follows in (1) [35]:

$$
x(k)=f(k)+w(k)
$$

The general threshold composes of the crude (hard, $h$ ), or the shrinkage (soft, $s$ ) thresholds, which are parameters applied to the coefficients resulted from the wavelet decomposition. All the coefficients with absolute value below the threshold, $t$ was forced to become zero in $h$ thresholding to produce legitimate wavelet transform. Alternatively, in $s$ thresholding, there is less severe distortion of the signal of interest while shrinking the coefficients above the threshold in absolute values [35]. An asymptotically optimal formula called sqtwolog or the universal threshold; $t$ was given by Donoho et al. [37] in (2):

$$
t=\sigma \sqrt{ }(2 \log n)
$$

where, $\sigma$ is estimate of noise level of, $n$ data points [38]. There are two ways to apply the threshold formula [39].

Hard Threshold: If $x$ is the set of wavelet coefficients, then threshold is given by (3):

$$
T(t, x)=\left\{\begin{array}{cl}
0 & \text { if }|x|<t \\
(x) & \text { otherwise }
\end{array}\right.
$$

Soft Threshold: All coefficients $\mathrm{x}$ that are less then threshold is zeroed (4):

$$
T(t, x)= \begin{cases}0 & \text { if }|x|<t \\ \operatorname{sign}(x)(|x|-t) & \text { otherwise }\end{cases}
$$

The threshold parameters consisting of specific threshold algorithms of minimaxi, heursure, sqtwolog and rigrsure performs thresholding based on the basic universal threshold formula [40], [38].

The minimaxi is also known as universal threshold uses the fixed threshold $t$, of choice to yield its performance for mean square error (MSE) against an ideal. The Stein Unbiased Risk Estimate (SURE) threshold performs level dependant thresholding rule where it computes a separate threshold for each detailed level based on SURE [41]. The rigrsure or also known as Sure Shrink algorithm chooses threshold $t$, by minimising the SURE for each wavelet level [38]. Finally, the heursure is a hybrid of the universal threshold of sqtwolog and rigrsure to compensate for lacking both algorithms [40]. Rigrsure and heursure thresholds are level dependant method of thresholding [42].

The minimaxi and rigrsure algorithm are more conservative and convenient when small details of function $\mathrm{f}$, lies in the noise areas, however the sqtwolog removes the noise more efficiently than the heursure algorithm [38]. Nevertheless, due to the lack of specific literature for these methods, all the threshold methods available were explored following the trial and error method, in search for the best denoising parameters. There are a wide range of wavelet families that can be used as wave filter for nutrient content determination namely Daubechies wavelets (db), Symlets (sym), Coiflets (coif), Biorthogonal wavelets (bior) and reverse biorthogonal wavelets (rbio) [42]. However, only four wavelets were randomly selected for this study based on research, and they include the $\mathrm{db} 4, \mathrm{db} 20$, haar and sym8 [40], [38], [44], [45]. The parameter selections and WD procedure used in this study is as shown in Fig. 2.

Another parameter called the threshold rescaling method for WD in Matlab had three selections of 'one', 'sln,' and 'mln' [46]. According to studies of Misiti et al. [47], the parameter ' $\sin$ ' relates to the basic noise model with unscaled noise. It performs threshold rescaling with a single estimation of level noise that is computed based on the first level coefficients of decomposition. The 'mln' method relates to basic noise model using non-white noise while performing thresholding, which is based on level dependant estimation of the noise at that decomposition level. The method 'one', however, generally follow the basic noise model.

For de-noising EEG signals, a study by Valencia et al. [40] indicated that $4^{\text {th }}$ level on hard and $5^{\text {th }}$ level on soft thresholding produced better $\mathrm{R}^{2}$ value as results. Hence for the selection of decomposition level, the levels of 1 to 5 were used individually following the trial and error method, assigned to each type of detailed approximation de-noising methods and $\mathrm{pa}^{\mathrm{r}}$ ameters. The decomposition level should be selected precisely since the useful signal components and unwanted components lie in different levels [48]. Finally, once all the selected parameters were applied, the signal was 
inverted and then reconstructed to obtain the estimated signal [22].

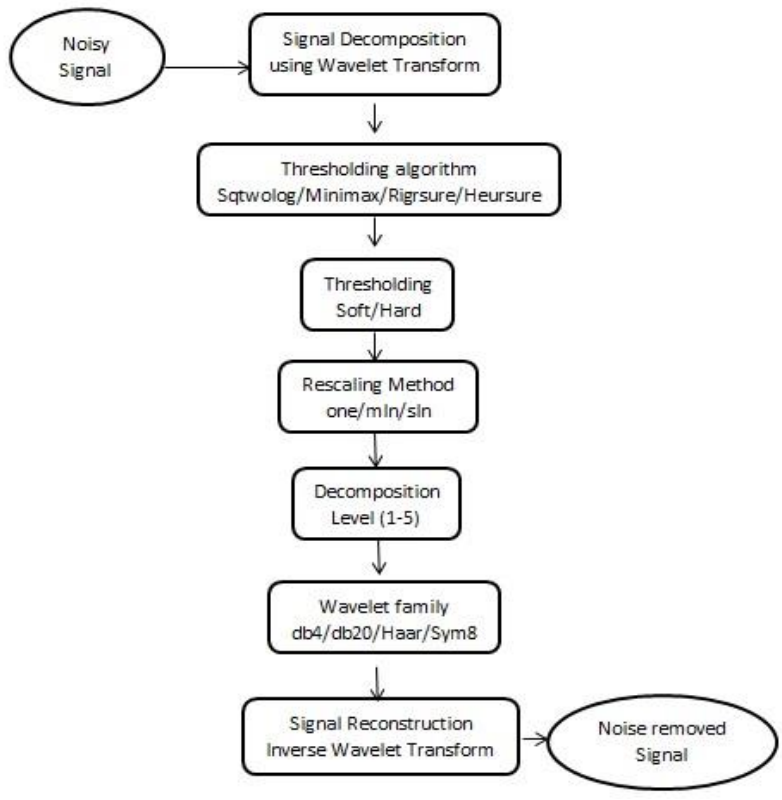

Fig. 2. Wavelet de-noising procedure and parameter selection.

\section{Partial Least Square Regression Analysis}

The optimal WD was identified based on the highest representation of $\mathrm{R}^{2}$ values of PLSR analysis for $\mathrm{F} 17$ of $\mathrm{N}$, $\mathrm{P}$, and $\mathrm{K}$ nutrients of age 5, 10 and 20 years respectively. The spectral reflectance data acquired using the FRS consists of 30 leaf samples from F17 of 30 palm trees (each age group). For each nutrient type, the spectral reflectance data set was randomly divided into calibration sets $(75 \%$ of the whole sample set) and prediction sets (25\% of the whole sample set) [49]. The PLSR analysed both $X$ and $Y$ matrices of the models simultaneously, to find the latent variable (LV) in $\mathrm{X}$ that best predicts the LV in $\mathrm{Y}$. This was achieved by maximising the covariance between $\mathrm{X}$ and $\mathrm{Y}$ [50]. The LV for the calibration model was selected to be 10 . A full crossvalidation with leave-one-out approach was executed for the calibration model to determine the optimal number of LVs [51]. For the prediction model, one out of four samples were manually selected as test samples since the data set is not in random order.

In order to generate a prediction model that had better representation of data from the sample group, about $6.7 \%$ (2 samples) of outliers were removed from the sample group as suggested by the PLSR analysis results. Both WD and PLSR analysis for the prediction nutrient contents were conducted in the Matlab (2013b) software environment. The results of all the parameter combinations for the WD techniques were evaluated using PLSR analysis for the highest $\mathrm{R}^{2}$ and lowest RMSE values [14], [49], [52], [53]. The PLSR analysis was used in order to have a standard comparison between the wavelet transform and chemometric pre-processing methods. From a study on the optimal pre-processing technique for nutrient determination in oil palm leaves using the conventional chemometric analysis approach, out of six techniques, the MSC was found to be the optimal technique [21]. Therefore, as comparison, the MSC technique of preprocessing was applied to the data acquired using PLSR.
For each nutrient type and age group, the spectral reflectance data set was randomly divided into $75 \%$ of calibration and $25 \%$ of prediction sets, to ensure similar parameters for comparison purpose. The PLS models were validated by comparisons of $\mathrm{R}^{2}$ and RMSE. The RMSE values were computed based on (5) [54]:

$$
\mathrm{RMSE}=\sqrt{\frac{\sum_{i=1}^{n}(\hat{\mathrm{y}} i-y i)^{2}}{n}}
$$

The PLSR model with high values of $\mathrm{R}^{2}$ and low values of RMSE for both calibration and prediction shows that it has a good representation of spectral data with nutrients. $\mathrm{R}^{2}$ was given by (6):

$$
\mathrm{R}^{2}=1-\left(\frac{\sum_{i=1}^{n}(y i-\overline{\mathrm{y}} i)^{2}}{\sum_{i=1}^{n}(y i-\hat{\mathrm{y}} i)^{2}}\right)
$$

where yi is observed data, $\bar{y}$ is predicted data and $\hat{y}$ is the mean of observed data.

In (6), the numerator is the sum of squared errors of our baseline model (SSE) of the regression model and the denominator is the total sum of squares (SST) [54]. The ideal model would be the one that fits all the data points perfectly so SSE would be 0 , such that $\mathrm{R}^{2}$ will be 1 , which indicates a perfect model. However, $\mathrm{R}^{2}$ can take any value between 0 and 1 , where values closer to 0 represent a poor fit whereas values closer to 1 represent a perfect fit. For example, if $\mathrm{R}^{2}$ was 0.90 , then it means $90 \%$ variations in dependent variable $\mathrm{Y}$ are explained by the independent variables present in the model.

\section{RESULTS AND DISCUSSION}

When a light beam propagates through plant leaves, it is partially reflected at the leaf surface and a fraction of it causes multiple scattering within the leaf tissues [55]. The reflection of diffused light is affected by multiple scattering related to internal structure, photons, air spaces, and airwater interfaces that refract light within the leaf [56]. Therefore, although measures were taken to reduce disturbance to the data acquired by cleaning the leaves in advance and using a clip on probe, there are still noise from the leaf structure itself and cosmic rays of earth which affects the data.

Palm's age of 2 years produces about 42 leaves a year whereas customary trees over 10 years produces about 20 leaves a year [57], [58]. For the leaves from the 5 years old palm tree, the de-noised spectral curves can be distinguished from the raw spectra, as seen in Fig. 3(a). The de-noised spectrum has slightly lower reflectance values compared to the raw original spectra. However, there is no visible difference between the different WD techniques used for $\mathrm{N}$, P, and K. Nevertheless, Fig. 3 (b) and (c) shows no differences between nutrients and raw original spectrum when looked upon by naked eyes. However, there is difference though, and this is seen through the $\mathrm{R}^{2}$ values of the PLSR since it shows the correlation between the reflectance and nutrients. A study by Bachy [59] revealed that nutrient $\mathrm{K}$ decreased with age while Knecht et al. [60] found that $\mathrm{N}$ had significant linear correlations whereas $\mathrm{P}$ and $\mathrm{Cl}$ content in leaves showed no relationship with age of plant. 


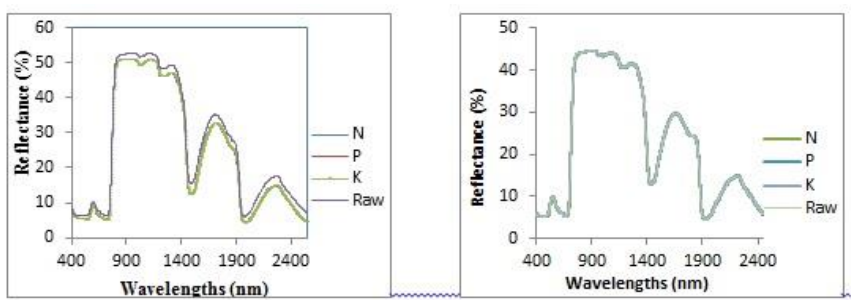

(a)

(b)

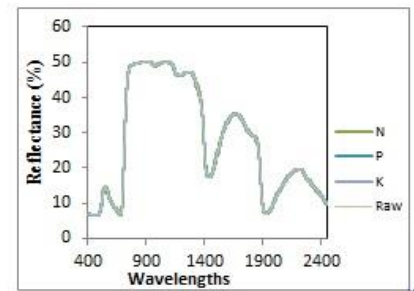

(c)

Fig. 3. Spectral curve of a sample of leaf reflectance of F17 for (a) 5 years, (b) 10 years, and (c) 20 years old of oil palm trees.

TABLE I: PLS REGRESSION OF BEST WD OF SPECTRAL DATA FOR F17 OF 5 YEARS OLD PALMS

\begin{tabular}{|c|c|c|c|c|c|c|c|c|}
\hline \multirow{3}{*}{ Nut* } & \multicolumn{4}{|c|}{ Raw } & \multicolumn{4}{|c|}{ Best De-noised Technique } \\
\hline & \multicolumn{2}{|c|}{ Calibration } & \multicolumn{2}{|c|}{ Prediction } & \multicolumn{2}{|c|}{ Calibration } & \multicolumn{2}{|c|}{ Prediction } \\
\hline & $\mathrm{R}^{2}$ & $\begin{array}{l}\text { RM } \\
\text { SE }\end{array}$ & $\mathrm{R}^{2}$ & $\begin{array}{c}\text { RM } \\
\text { SE }\end{array}$ & $\mathrm{R}^{2}$ & $\begin{array}{c}\text { RM } \\
\text { SE }\end{array}$ & $\mathrm{R}^{2}$ & $\begin{array}{c}\mathrm{RM} \\
\mathrm{SE}\end{array}$ \\
\hline $\mathrm{N}$ & 0.84 & 0.03 & 0.97 & 0.04 & 0.89 & 0.03 & 0.97 & 0.04 \\
\hline $\mathrm{P}$ & 0.83 & 0.12 & 0.68 & 0.07 & 0.90 & 0.09 & 0.68 & 0.07 \\
\hline $\mathrm{K}$ & 0.78 & 0.02 & 0.89 & 0.02 & 0.79 & 0.02 & 0.95 & 0.02 \\
\hline
\end{tabular}

*Note: Nutrients (best de-noise parameters): N (sqwotolog-h-one-4-haar), P (heursure-h-one-5-sym8), K (rigrsure-h-one-5-sym8).

It was found that different nutrients and age groups required different techniques of WD to provide the best $\mathrm{R}^{2}$ value as results of PLSR. The results for prediction models of 5 years old group are shown in Table I. K nutrient had best results for calibration and prediction model using WD pretreatment compared to raw spectra. However, both $\mathrm{N}$ and $\mathrm{P}$ had higher $\mathrm{R}^{2}$ value of calibration for WD compared to raw spectra with the same $\mathrm{R}^{2}$ and root mean square error (RMSE) values for prediction.

Based on the results shown in Table II and III, nutrients N, $\mathrm{P}$, and $\mathrm{K}$ of both the 10 and 20 years old palms had significantly higher results of $\mathrm{R}^{2}$ value for prediction using WD compared to raw spectra. The difference in the results of 10 and 20 years old palm were more obviously reflected in the leaf spectra probably because the mature and older palms has strong growth establishment, which was reflected in its leaf structure compared to the immature palms that were still in the growing stage.

TABLE II: PLS REGRESSION OF BEST WD OF SPECTRAL DATA FOR F17 OF

\begin{tabular}{|c|c|c|c|c|c|c|c|c|}
\hline \multirow{3}{*}{ Nut* } & \multicolumn{4}{|c|}{ Raw } & \multicolumn{4}{|c|}{ Best De-noised Technique } \\
\hline & \multicolumn{2}{|c|}{ Calibration } & \multicolumn{2}{|c|}{ Prediction } & \multicolumn{2}{|c|}{ Calibration } & \multicolumn{2}{|c|}{ Prediction } \\
\hline & $\mathrm{R}^{2}$ & $\begin{array}{c}\text { RM } \\
\text { SE }\end{array}$ & $\mathrm{R}^{2}$ & $\begin{array}{c}\text { RM } \\
\text { SE }\end{array}$ & $\mathrm{R}^{2}$ & $\begin{array}{c}\text { RM } \\
\text { SE }\end{array}$ & $\mathrm{R}^{2}$ & $\begin{array}{l}\text { RM } \\
\text { SE }\end{array}$ \\
\hline $\mathrm{N}$ & 0.96 & 0.03 & 0.04 & 0.14 & 0.95 & 0.03 & 0.95 & 0.31 \\
\hline $\mathrm{P}$ & 0.93 & 0.00 & 0.86 & 0.01 & 0.97 & 0.00 & 0.95 & 0.00 \\
\hline K & 0.92 & 0.07 & 0.85 & 0.21 & 0.94 & 0.06 & 0.99 & 0.27 \\
\hline
\end{tabular}

*Note: Nutrients (best de-noise parameters): N(sqwotolog-h-one-5-db20), P (minimaxi-h-mln-5-haar), K (sqwotolog-h-mln-5-haar).

For the general threshold, it was found that all three age groups and nutrients resulted in hard threshold except for $\mathrm{K}$ nutrient of 20 years old palm, which has soft threshold as the best WD technique. This was in contrary to the results that found soft threshold to outperform hard threshold from study by Messer et al. [46] on heart sound of phonocardiograms signal recordings (at 2500 samples per second) and by Chhantyal et al. [42] for ultrasonic time-domain reflectometry signals for molten lead.

TABLE III: PLS REGRESSION OF BEST WD OF SPECTRAL DATA FOR F17 OF 20 YEARS OLD PALMS

\begin{tabular}{cccccccccc}
\hline & \multicolumn{4}{c}{ Raw } & \multicolumn{3}{c}{ Best De-noised Technique } \\
\cline { 2 - 9 } Nut* & \multicolumn{3}{c}{ Calibration } & \multicolumn{2}{c}{ Prediction } & \multicolumn{2}{c}{ Calibration } & \multicolumn{2}{c}{ Prediction } \\
\cline { 2 - 9 } & \multirow{2}{*}{$\mathrm{R}^{2}$} & $\mathrm{RM}$ & \multirow{2}{*}{$\mathrm{R}^{2}$} & $\mathrm{RM}$ & \multirow{2}{*}{$\mathrm{R}$} & $\mathrm{RM}$ & \multirow{2}{*}{$\mathrm{R}^{2}$} & $\mathrm{RM}$ \\
& & $\mathrm{SE}$ & & $\mathrm{SE}$ & & $\mathrm{SE}$ & & $\mathrm{SE}$ \\
\hline $\mathrm{N}$ & 0.94 & 0.05 & 0.50 & 0.34 & 0.95 & 0.05 & 0.92 & 0.10 \\
$\mathrm{P}$ & 0.82 & 0.00 & 0.24 & 0.02 & 0.91 & 0.00 & 0.77 & 0.02 \\
$\mathrm{~K}$ & 0.86 & 0.04 & 0.19 & 0.13 & 0.86 & 0.04 & 0.97 & 0.25 \\
\hline *Note: & Nutrient (best de-noise parameters): N (heursure-h-one-4-haar), $\mathrm{P}$ \\
(minimaxi-h-one-5-db20), K (heursure-s-mln-5-haar).
\end{tabular}

Out of the three rescaling methods, the 'one' which follows the basic noise model was best for $\mathrm{N}, \mathrm{P}$, and $\mathrm{K}$ of immature palms, only for $\mathrm{N}$ of mature palms and $\mathrm{N}$ and $\mathrm{P}$ of older palms. The 'mln' as a rescaling method which relates to level dependant estimation of the noise had best results for $\mathrm{P}$ and $\mathrm{K}$ of mature palms and $\mathrm{K}$ of older palms. This result was similar to ' $\mathrm{mln}$ ' being the best threshold rescaling method for WD of real phonocardiography signal that was recorded by mobile devices but was in contrast to 'sln' being the best WD for generated phonocardiogram signals [61], [46].

The specific threshold algorithm had mixed results; however, in general, the heursure and sqtwolog gave best results probably because sqtwolog is the universal thresholding with highest resolution level, proving that $\mathrm{N}$ of immature palms and $\mathrm{N}$ and $\mathrm{K}$ of mature palms are well reflected in its spectral reflectance data. Since heursure is a hybrid of sqtwolog and rigrsure, it could tackle both aspects of wavelength sparcity, giving higher correlation for $\mathrm{P}$ of immature palms and $\mathrm{N}$ and $\mathrm{K}$ of older palms.

However, the minimaxi was best for $\mathrm{P}$ of 10 and 20 years old palms due to small details of function that lies in the noise range, while the rigrsure algorithm best suited nutrient $\mathrm{K}$ of 5 years old palm, where the majority of wavelet coefficients are non-zeroes, proving that the $\mathrm{K}$ content of immature palms reflected in the spectral reflectance data that was not sparse. However, Zhu et al. [62] reported that the threshold algorithms selection of Birge-Massart and Penalty performed well compared to SURE, sqtwolog, heuristic SURE, and minimaxi sets due to their high threshold values.

As for the wavelet family selection, the haar and db20 were found to be best for most nutrients and age group whereas sym8 was best for spectral representation of $\mathrm{P}$ and $\mathrm{K}$ nutrient prediction of 5 years old palms. This was similar to the report on wavelets of sym8 and db family (specifically db4) having similar results for data compression of NIR spectroscopy with spectra collected from 227 different sheets of cellulose-derivative in the wavelengths range of 400 to $2500 \mathrm{~nm}$ with minimal loss of information [45]. In addition, haar wavelet was found best for the WD of low Gaussian noise, with highest $\mathrm{R}^{2}$ value of 0.99 at level 5 when combined with rigrsure and s threshold [40]. 
In overall, the level 5 was suitable for most nutrients and palm's age groups; however, the level 4 best suited for 5 years old palms for both $\mathrm{N}$ and $\mathrm{K}$ nutrients. This was similar to Tahani et al. [38] and Messer et al. [46] where the level 5 was found to be the best WD for fault detection of wind turbine system and phonocardiograms signal. Another study by Zhu et al. [62] on noise elimination of charged couple device near infrared (CCD-NIR) spectra of apple using DWT had good results with $\mathrm{db}$, sym, and bior wavelet families with level 2 as the best decomposition level and bior 3.3 as optimal wavelet. However, the pairing of $\mathrm{db} 5$ with decomposition of level 6 was found to be the optimum selection based on lowest RMSE to perform DWT de-noising for microchip capillary electrophoresis (MCE) [63]. Hence probably more experiment on the optimal level is welcomed for better understanding of the noise at different levels in leaf spectral reflectance.

As for the optimal combination of WD parameters, there was no one general combination that could best represent spectral reflectance data of nutrients $\mathrm{N}, \mathrm{P}$, and $\mathrm{K}$ of 5,10 , and 20 years old palms. However, another study by Chen and Zhang [44] as well as Joy et al. [37] revealed that the rigrsure algorithm when paired with $\mathrm{db} 4$ and $\mathrm{db} 3$ of level 5 gave best RMSE and signal to noise ratio (SNR) when tested with a noisy signal to its general original signal.

A summary of the de-noising techniques of spectral reflectance data for F17 of oil palm leaves is shown in Table IV. In this table, a side-by-side comparison of optimal WD method with optimal chemometric pre-processing method of the MSC technique and original spectral was presented. The MSC handles both additive and multiplicative effects of light scattering using simple baseline shifting for each individual spectrum. This is in contrast to WD technique that uses thresholds that shrinks the empirical wavelet coefficients to zero which suppresses noise entirely while remaining the original sharp features in the reconstructed signal that amplifies signals related to biochemical properties.

TABLE IV: SUMMARY OF BEST PRE-PROCESSING TECHNIQUES FOR F17

\begin{tabular}{cccccccc}
\multicolumn{1}{c}{$\begin{array}{c}c \\
\text { Age } \\
\text { (yr) }\end{array}$} & Nut & \multicolumn{2}{c}{ RAW } & \multicolumn{2}{c}{ MSC } & \multicolumn{2}{c}{$\begin{array}{c}\text { Wavelet } \\
\text { De-noising }\end{array}$} \\
\cline { 3 - 8 } & & $\mathrm{R}^{2}$ & $\begin{array}{c}\text { RM } \\
\text { SEP }\end{array}$ & $\mathrm{R}^{2}$ & $\begin{array}{c}\text { RM } \\
\text { SEP }\end{array}$ & $\mathrm{R}^{2}$ & $\begin{array}{c}\text { RM } \\
\text { SEP }\end{array}$ \\
\hline 5 & $\mathrm{~N}$ & 0.97 & 0.04 & 0.91 & 0.34 & 0.97 & 0.04 \\
& $\mathrm{P}$ & 0.68 & 0.07 & 0.72 & 0.00 & 0.68 & 0.07 \\
& $\mathrm{~K}$ & 0.89 & 0.02 & 0.90 & 0.03 & 0.95 & 0.0 \\
& & & & & & & \\
10 & $\mathrm{~N}$ & 0.04 & 0.14 & 0.68 & 0.07 & 0.95 & 0.31 \\
& $\mathrm{P}$ & 0.86 & 0.01 & 0.13 & 0.01 & 0.95 & 0.00 \\
& $\mathrm{~K}$ & 0.85 & 0.21 & 0.82 & 0.17 & 0.99 & 0.27 \\
& & & & & & & \\
20 & $\mathrm{~N}$ & 0.50 & 0.34 & 0.92 & 0.23 & 0.92 & 0.10 \\
& $\mathrm{P}$ & 0.24 & 0.02 & 0.25 & 0.01 & 0.77 & 0.02 \\
& $\mathrm{~K}$ & 0.19 & 0.13 & 0.10 & 0.10 & 0.97 & 0.25 \\
\hline
\end{tabular}

In Table IV, the PLS prediction model using WD technique with respect to nutrient shows higher representation of $\mathrm{R}^{2}$ values than raw and MSC treated spectral. The WD method also has the lower RMSE values ranging from 0.00 to 0.31 for $\mathrm{F} 17$ from palms of all three ages. The highest $\mathrm{R}^{2}$ with the value of 0.99 was for nutrient $\mathrm{K}$ of 10 years old palms, using sqtwolog algorithm of hard threshold at decomposition level 5 with haar wavelet and 'mln' threshold rescaling WD. This was very similar to results of Valencia et al. [40] except by using 'sln' as rescaling threshold. Nevertheless, only the nutrient $\mathrm{P}$ of 5 years old palm had low $\mathrm{R}^{2}$ value for prediction model. It was also observed that for some of the nutrients the prediction $\mathrm{R}^{2}$ was found to be higher than its calibration $\mathrm{R}^{2}$ probably due to the difference in the sample size. The WD was found to be more suitable for this non-linear biological data compared to the conventional statistical approach.

\section{CONCLUSION}

In fulfilment of the first objective, it was found that each type of nutrient had different combination of wavelet denoising technique as its optimal method of pre-processing for oil palm F17. In addition, the different age group of palms also had different combination of parameters that make the best WD techniques. This finding was essential to ensure best pre-processing in preparation for further analysis. As for the second objective, the WD technique was proven useful to improve the analysis of signal significantly compared to raw and statistical pre-processing method. As conclusion, it was evident from this study that the WD method had better predictive correlation than original spectra by having the best $\mathrm{R}^{2}$ of 0.95 for $\mathrm{N}$ of 10 years old palm, 0.95 for $\mathrm{P}$ of 10 years old palm, and 0.99 for $\mathrm{K}$ of 10 years old palm.

\section{ACKNOWLEDGMENT}

We would like to thank Dr. Xaviar Arulandoo and Dr. Vijiandran Juvarajah from the Research and Development Department of United Plantations Bhd., Malaysia for their hospitality and all the funding sources for their financial support.

\section{REFERENCES}

[1] E. Saxon, "The root of the problem", in Palm Oil, Union of Concerned Scientists, 2011, pp.1-15.

[2] A. D. Amirrudin, F. M. Muharam, and N. Mazlan, "Assessing leaf scale measurement for nitrogen content of multi-ages oil palm: performance of discriminant analysis and support vector machine classifiers". International Journal of Remote Sensing, vol. 38, pp. 7260-7280, 2017.

[3] S. K. Behera, B. N. Rao, K. Suresh, and K. Manoja, "Soil nutrient status and leaf nutrient norms in oil palm; plantations grown on Southern Plateau of India", in Proceedings of the National Academy of Sciences, Section B: Biological Sciences, pp. 691-697, vol 86(3), India, 2015.

[4] A. R. Anuar, K. J. Goh, T. B. Heoh, and O. H. Ahmed, "Spatial temporal yield trend of oil palm as influenced by nitrogen fertilizer management", American Journal of Applied Sciences, vol 5(10), pp. $1376-1383,2008$.

[5] P. D. Turner, and R. A. Gillbanks. "Oil palm cultivation and management", Incorporated Society of Planters, 2nd ed. Kuala Lumpur, 2003.

[6] H. L. Foster, "Management for large and sustainable yields", in Oil Palm, Fairhurst TH, Härdter R, editors. Potash \& Phosphate Institute/Potash \& Phosphate Institute of Canada (PPI/PPIC), pp. 231257, 2003.

[7] K. C. Teoh, P. S. Chew, C. S. Chow, and A. C Soh, "A study of the seasonal fluctuation in leaf nutrient levels in oil palms in Peninsular Malaysia", in Inc. Soc. of Planters, Pushparajah E, Chew PS. Editors, The Oil Palm in the Eighties (Vol. II), pp. 13-38, Kuala Lumpur, 1982.

[8] H. Broeshart, J. D. Ferwerda, and W. G. Kovachich, "Mineral deficiency symptoms of the oil palm", Plant and Soil, Martinus Nijhoff, The Hague/Kluwer Academic Publishers, vol 8(4), pp. 289300, 1957. 
[9] T. H. Fairhurst, J. P. Caliman, R. Hardter and C. Witt, "Nutrient Disorders and Nutrient Management", in Oil palm, Potash \& Phosphate Institute (PPI) / Potash \& Phosphate Institute Canada (PPIC) and International Potash Institute (IPI); French Agricultural Research Centre for International Development (CIRAD) and CTP Holdings, Oil Palm Series, Vol 7, 2004 (Reprinted in 2006, 2010).

[10] R. H. V. Corley, and P. B. Tinker, "The Oil Palm", Blackwell Sciences Ltd, Oxford, 4th ed., United Kingdom, 2003.

[11] K. J. Goh, Sg. Po. Buloh, "Fertilizer recommendation system for oil palm: estimating the fertilizer rates", in: Proceedings of MOSTA Best Practices Workshops - Agronomy and Crop Management. 2005.

[12] A. M. Tarmizi, A. B. Hamdan, Z. Z. Zin, and T. D. Mohd, "The effects of $\mathrm{N}, \mathrm{P}$, and $\mathrm{K}$ fertilizers on oil palm bunch components", in Proceedings of the National Seminar on Opportunities for Maximizing Production through Better OER and Offshore Investment in Oil Palm, PORIM, pp.22. Bangi, 1998.

[13] B. Jamshidi, S. Minaei, E. Mohajerani, and H. Ghassemian, "Reflectance Vis/NIR spectroscopy for non-destructive taste characterisation of Valencia oranges", Journal of Computers and Electronics in Agriculture, vol. 85, pp. 64-69, 2012.

[14] M. N. Nawi, T. Jensen, and G. Chen, "Application of spectroscopic method to predict sugar content of sugarcane internodes", Journal of Tropical Agriculture and Food Science, vol.41(2), pp. 211-220, 2013a.

[15] A. Rohman, Y. B. CheMan, A. Ismail, and P. Hashim, "Application of FTIR spectrometer for the determination of virgin coconut oil in binary mixtures with olive and palm oil", Journal of American Oil Chemists Society, vol. 87, pp. 601-606, 2010.

[16] W. Ammawath, Y. B. CheMan, R. R. B. Abdul, and B. S. Baharin, "A Fourier transform infrared spectroscopic method for determining butylated-hydroxytoluene in palm olein and palm oil", Journal of American Oil Chemists Society, vol. 83 (3), 2006.

[17] H. R. Xu, Y. B. Ying, X. P. Fu, and S. P. Zhu, "Near-infrared spectroscopy in detecting leaf minor damage on tomato leaf", Biosystems Engineering, vol. 96, pp. 447-454, 2007.

[18] A. H. Al-Abbas, R. Barr, J. D. Hall, F. L. Crane, and M. F. Baumgardner, "Spectra of normal and nutrient-deficient maize leaves", Journal of Agronomy, vol. 66, pp. 16-20, 1974.

[19] J. R. Thomas, and G. F. Oerther, "Generic combustion method for determination of crude protein in feeds: a collaborative study", $J$. Assoc. Off. Anal Chem, vol. 72, pp.770-774, 1972

[20] K. Khorramnia, L. R. Khot, A. R. M. Shariff, R. Ehsani, S. Mansor, A A. Rahim, "Oil palm leaf nutrient estimation by optical sensing techniques", $A S A B E$, vol. 57(4), pp.1267-1277, 2014.

[21] H. A. J. Jayaselan, W. I. W. Ismail, M. N. Nawi, and A. R. M. Shariff, "Determination of the optimal pre-processing technique for spectral data of oil palm leaves with respect to nutrient", Journal of Science and Technology, vol. 26(3), pp. 1169-1182, 2018.

[22] L. Hexiao, S. LaiJun, L. Mingliang, Q. Haibo, L. Wenbo, W. Lekai, D. Changjun, Z. Naixin, L. Jin, "Determination of wet gluten in wheat based on wavelet de-noising and PLS", in the IEEE International Conference: New Technology of Agricultural Engineering, 2011, pp. 958-962.

[23] L. Ebadi, H. Z. M. Shafri, S. B. Mansor, and R. Ashurov, "A review of applying second-generation wavelets for noise removal from remote sensing data", Environmental Earth Sciences, vol. 70(6), pp. 26792690,2013

[24] I. Daubechies, "The wavelet transform, time-frequency localization and signal analysis", Transactions on Information Theory, vol. 36(5), pp. 961-1005, 1990.

[25] M. Kania, M. Fereniec, and R. Maniewski, "Wavelet de-noising for multi-lead high resolution ECG signals", Journal of Measurement Science Review, vol. 7(2), pp. 30-33, 2007.

[26] M. Aminghafari, N. Cheze, and J. M. Poggi, "Multivariate de-noising using wavelets and principle component analysis", Journal of Computational Statistics \& Data Analysis, vol. 50, pp. 2381-2398, 2006.

[27] B. Ergen, "Signal and image de-noising using wavelet transform", Advances in Wavelet Theory and Their Applications in Engineering, Physics and Technology, pp. 496-514, 2012.

[28] X. Zhe, Z. Hua, L. Zhuo, and H. Wenjiang, "Application of de-noising method for wheat spectral signal", in: Chinese Control and Decision Conference, CCDC. 2009; pp. 2040-2042.

[29] T. H. Fairhurst, and E. Mutert, "Interpretation, and Management of Oil Palm Leaf Analysis Data”, Better Crops International, vol. 13(1), pp. 48-51, 1999.

[30] E. Pushparajah. (1994). Leaf analysis and soil testing for plantation tree crops. pp. 1-9.

Available: http://www.agrifoodgateway.com/articles/leaf-analysisand-soil-testing-plantation-tree-crops.
[31] K. J. Goh, C. P. Soon, and K. K. Kiang, "K nutrient for mature oil palm in Malaysia", International Potash Institute Basel, Switzerland, IPI Research Topics, vol. 17, 1993.

[32] A. Pimstein, A. Karnieli, S. K. Bansal, and D. J. Bonfil, "Exploring remotely sensed technologies for monitoring wheat potassium and phosphorus using field spectroscopy", Field Crops Research, vol. 121, pp. $125-135,2011$.

[33] M. A. Bechlin, F. M. Fortunato, R. M. D. Silva, E. C. Ferreira, and J. A. G Neto, "A simple and fast methods for assessment of the nitrogenphosphorus-potassium rating of fertilizers using high resolution continuum source atomic and molecular absorption spectrometry", Spectrochimica Acta Part B, vol. 101, pp. 240-244, 2014.

[34] G. A. Blackburn, and J. G. Ferwerda, "Retrieval of chlorophyll concentration from leaf reflectance spectra using wavelet analysis", Journal of Remote Sensing Environment, vol. 112, pp. 1614-1632, 2008.

[35] O. Farooq, and S. Datta, "Wavelet-based de-noising for robust feature extraction for speech recognition", Electronics Letters, vol. 39(1), pp 163-165, 2003.

[36] D. F. Guo, W. H. Zhu, Z. M. Gao, and J. Q. Zhang, “A study of wavelet thresholding de-noising", in Signal Processing Proceedings of WCCCICSP $5^{\text {th }}$ International Conference, 2000, pp. 329-332.

[37] D. L. Donoho, and I. M. Johnston, "De-noising by soft-thresholding", Trans. Inf. Theory, vol. 41(3), pp. 613-627, 1995.

[38] J. Joy, S. Peter, and N. John, "De-noising using soft thresholding", International Journal of Advanced Research in Electrical, Electronics and Instrumentation Engineering, vol. 2(3), pp. 1027-1032, 2013.

[39] B. Tahani, B. Boumedyen, A. M. Naceur, O. P. Fogh, and A. Christophe, "Multiple fault detection based on wavelet de-noising: application on wind turbine system", in $25^{\text {th }}$ Mediterranean Conference on Control and Automation (MED) Valletta, Malta, 2017, pp.419-423.

[40] D. Valencia, D. Orejuela, J. Salazar, and J. Valencia, "Comparison analysis between rigrsure, sqtwolog, heursure, and minimaxi techniques using hard and soft thresholding methods", presented at Signal Processing, Images and Artificial Vision (STSIVA), XXI Symposium, IEEE, August, pp. 1-5, 2016.

[41] S. Madhu, H. B. Bhavani, and S. Sumathi, "Performance analysis of thresholding techniques for de-noising of simulated partial discharge signals corrupted by Gaussian while noise", in International Conference on Power and Advanced Control Engineering (ICPACE), 2015, pp. 399-404.

[42] K. Chhantyal, H. Viumdal, and S. Mylvaganam, "Improving ultrasonic multi-level measurements with wavelets-results from separators and smelters", in: International Ultrasonic Symposium Proceedings (IUS), IEEE, September 18, pp.1-5, 2016.

[43] G. A. Blackburn, "Wavelet decomposition of hyperspectral reflectance data for quantifying photosynthetic pigment concentrations in vegetation", presented at Proceedings of the XXth ISPRS Congress Commission, July, vol. 7, pp.12 - 23, 2004

[44] S. Chen, and H. Zhang, "Detection of underwater acoustic signal from ship noise based on WPT method", in: $4^{\text {th }}$ International Workshop on Chaos-Fractals Theories and Applications, pp.324-327, 2011.

[45] J. Trygg, and S. Wold, "PLS regression on wavelet compressed NIR spectra", Journal of Chemometrics and Intelligent Laboratory Systems, vol. 42, pp. 209-220, 1998.

[46] S. R. Messer, J. Agzarian, and D. Abbott, "Optimal wavelet de-noising for phonocardiograms", Journal of Microelectronics, vol. 32, pp. 931941, 2001.

[47] M. Misiti, T. Misiti, G. Oppenheim, and J. M. Poggi, "Wavelet toolbox: for use with Matlab", The Math Works Inc, 1996.

[48] P. K. Jain, and A. K. Tiwari, "An adaptive thresholding method for the wavelet based de-noising of phonocardiogram signal", Journal of Biomedical Signal Processing and Control, vol. 38, pp. 388-399, 2017.

[49] N. M. Nawi, T. Jensen, and G. Chen, "The application of spectroscopic methods to predict sugarcane quality based on stalk cross-sectional scanning", Journal of American Society of Sugar Cane Technologists, vol. 32, pp. 6-27, 2012.

[50] R. D. Tobias, "An introduction to partial least square regression", SAS Institute Inc. Cary, NC. Available: https://stats.idre.ucla.edu/wpcontent/uploads/2016/02/pls.pdf. 2016.

[51] N. M. Nawi, G. Chen, T. Jensen, and S. A. Mehdizadeh, "Prediction and classification of sugar content of sugarcane based on skin scanning using visible and shortwave near infrared", Journal of Biosystems Engineering, vol. 115(2), pp. 154-161, 2013b.

[52] Z. Yao, K. Sakai, X. Ye, T. Akita, Y. Iwabuchi, and Y. Hoshino, "Airborne hyperspectral imaging for estimating acorn yield based on the PLS B-matrix calibration technique", Ecological Informatics, vol. 3, pp. 237-244, 2008. 
[53] E. M. A. Rahman, O. Mutanga, J. Odindi, E. Adam, A. Odindo, and R. Ismail, "Estimating Swiss chard foliar macro- and micronutrient concentrations under different irrigation water sources using groundbased hyperspectral data and four partial least squares (PLS)-based (PLS1, PLS2, SPLS1 and SPLS2) regression algorithms", Computers and Electronics in Agriculture, vol. 132, pp. 21-33, 2017.

[54] P. M. Hansen, and J. K. Schjoerring, "Reflectance measurement of canopy biomass and nitrogen status in wheat crops using normalized difference vegetation indices and partial least squares regression", Journal of Remote Sensing of Environment, vol. 86, pp. 542-553, 2003.

[55] H. W. Gausman, and W. A. Allen, "Optical parameters of leaves of 30 plant species”, Plant Physiol,vol. 52, pp. 57-62, 1973.

[56] S. Jacquemoud, and S. L. Ustin, "Modeling leaf optical properties" Available: http://photobiology.info/Jacq_Ustin.html.

[57] N. Mustafa, N. Ya'acob, Z. A. Latif, A. L. Yusof, "Quantification of oil palm tree leaf pigment (Chlorophyll a) concentraion based on their age", Jurnal Teknologi (Sciences \& Engineering), vol. 75(11), pp. 129134, 2015.

[58] C. J. Breure, "Rate of leaf expansion: A criterion for identifying oil palm (Elaeis guineensis Jacq.) types suitable for planting at high densities", Wageningen Journal of Life Sciences, vol. 57, pp. 141-147, 2010.

[59] A. Bachy, "Foliar diagnosis of oil palm. Effect of age of trees", Oleagineux, vol. 20, pp. 227-230, 1965.

[60] J. C. X. Knecht, R. Ramachandran, and R. Narayanan, "Variation of leaf nutrient contents with age of plants in oil palm leaf sampling", Oleagineux, vol. 32(4), pp. 139-147, 1977.

[61] D. Gradolewski, and G. Redlarski, "Wavelet-based de-noising method for real phonocardiography signal recorded by mobile device in noisy environment", Journal of Computers in Biology and Medicine, vol. 52, 119-129, 2014.

[62] D. Zhu, B. Ji, C. Meng, B. Shi, Z. Tu, and Z. Qing, "Study of wavelet de-noising in apple's charge-coupled device near-infrared spectroscopy", Journal of Agriculture, Food and Chemical, vol. 55 (14), pp. 5423-5428, 2007.

[63] B. F. Liu, Y. Sera, N. Matsubara, K. Otsuka, and S. Terabe, "Signal de-noising, and baseline correction by discrete wavelet transform for microchip capillary electrophoresis", Electrophoresis, vol. 24(18), pp.3260-3265, 2003.

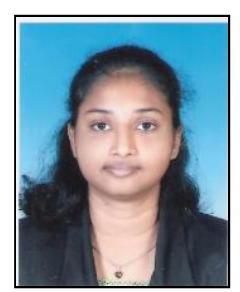

Helena A. J. Jayaselan originated from Teluk Intan, Perak, Malaysia is very fond of the oil palm crop since the land was widely cultivated with this crop commercially.

She completed her Bachelor's Degree in Agricultural Engineering at Universiti Putra Malaysia in the year 2008. Her final year project was focused on the study of oil palm tree, its method of cultivation and the engineering of the oil palm mill and machines assisted with a short internship at the local oil palm mill in Teluk Intan. Then she completed her Masters of Science in Agriculture Engineering and Automation in year 2011 at the same university, emphasizing on a more efficient harvesting experience by introducing automation to the existing harvesters. Finally, with a doctorate titled Robotics in Agricultural Engineering from Universiti Putra Malaysia completed in 2017, she researched ways to process nutrients' information in real time using wavelet analysis.

Dr. Jayaselan was a lecturer in Engineering Department of First City University College from Feb 2012 to May 2013 and Taylors College from May 2018 to May 2019. Apart from being a member of the Institute of Engineering Malaysia (IEM), she focuses on field of oil palm research, automation and robotics. 